${ }^{1}$ Programa de Biología Celular y Molecular, Instituto de Ciencias Biomédicas (ICBM), Facultad de Medicina, Universidad de Chile. Santiago, Chile.

2Programa de Microbiología y Micología, Instituto de Ciencias Biomédicas (ICBM), Facultad de Medicina, Universidad de Chile. Santiago, Chile.

Los autores declaran no tener conflictos de interés. Trabajo no recibió financiamiento.

Recibido el 15 de noviembre de 2019, aceptado el 25 de abril de 2020.

Correspondencia a: Carlos G. Osorio Abarzúa

Programa de Microbiología y Micología, Instituto de Ciencias Biomédicas (ICBM), Facultad de Medicina, Universidad de Chile. Santiago, Chile. gonosorio@med.uchile.cl

\section{El arribo de la teoría celular a Chile: Dr. Vicente Izquierdo Sanfuentes}

\author{
VALERIA SABAJ DIEZ ${ }^{1}$, CARLOS G. OSORIO A. ${ }^{2}$
}

\section{Dr. Vicente Izquierdo Sanfuentes and the arrival of the cellular theory in Chile}

Vicente Izquierdo Sanfuentes was a leading physician, researcher and academic of the School of Medicine of the University of Chile in the period 18811912. Dr. Izquierdo began his medical training at the Faculty of Medicine of the University of Chile (1872-1875) and then received a scholarship to continue his studies with the prominent researchers Wilhelm Hiss (1875-1877) at the University of Leipzig and Wilhelm Waldeyer at the University of Strasbourg (1877-1879) in Germany. After returning to Chile, he was appointed first professor of Histology (1881), initiating the first course of this subject in 1883. His main academic achievements and his foundational role in the origin and development of biology in Chile stand out in his work.

(Rev Med Chile 2020; 148: 528-534)

Key words: Cell Biology; Chile; Histology; History of Medicine.
L a historia de las ciencias se entreteje con la historia política, filosófica y características producción y posterior reproducción de comunidades científicas en diversos lugares del mundo no es algo trivial; no se trata de simple difusión, es un hecho sociológico complejo y diverso ${ }^{1}$.

En el ámbito de la biología, la teoría celular, la de la herencia de Mendel y la de la evolución, nacieron en países europeos. Tanto al interior del país como entre los diferentes países europeos se observan diferentes tiempos de introducción, aceptación y establecimiento de comunidades científicas dedicadas al estudio de estas áreas. Poco se ha discutido cómo ocurrió este fenómeno en países más alejados de Europa.

En Chile, como en el resto del mundo, la biología celular tiene sus antecesores directos en disciplinas como la Histología y la Zoología, pero aun antes, es la Historia Natural la madre de esta nueva ciencia. La historia de la enseñanza de la Historia Natural y Zoología en Chile y su rol en el inicio de los estudios biológicos se revisará en un trabajo paralelo y complementario a este (el nacimiento de la enseñanza biológica en Chile, manuscrito en preparación).

\section{Los albores de la biología celular}

Cuando aludimos hoy a la biología celular, lo primero que viene a la mente es la teoría celular. Al referirnos a esta teoría, lo hacemos en forma de aforismos que resumen ciertos principios básicos de lo que conocemos respecto a la forma de organización que tienen los organismos vivos, no presentamos, en realidad, una teoría propiamente tal, que pretenda predecir un fenómeno. Sin embargo, en la primera mitad del siglo XIX, efectivamente se presentó como una predicción novedosa respecto a la organización de los seres vivos. De esta forma, la teoría celular se constituyó como una explicación de los organismos y de la vida como resultado de un mecanismo. Para llegar a este estado de las cosas, fue necesario que confluyeran una pregunta y un instrumento, ¿cómo están organizados los seres vivos? y el microscopio, respectivamente ${ }^{2}$. 
Aunque el uso del microscopio se remonta al siglo XVII, destacando aquí la clásica obra "Micrographia" (1665) de Robert Hooke (16351703), quien describió la estructura microscópica de tallos y hojas vegetales, introduciendo por primera vez el término "cellula" (celdilla hueca), y el de Anton van Leeuwenhoek (1632-1723) quien analizó la estructura de tejidos de músculos estriados cardíacos, así como los bastones de la retina y células bacterianas y protozoos, el estudio del mundo microscópico constituía más bien un pasatiempo que una ciencia. Pese a esto, hubo descripciones muy interesantes, como las de glóbulos rojos por Jan Swammerdam (1637-1680) y tejido óseo por Crisóstomo Martínez (1638-1694) y las de Marcello Malpighi (1628-1694), quien utilizó el término "sacculae" o "utriculi" para las futuras células y tubos para los vasos sanguíneos que estudió mediante una novedosa metodología para la época, que permitía la utilización de finas secciones de tejido. Es probable que la elección de los nuevos nombres de sacculae/utriculi en vez de cellula ya tuviese como objetivo destacar el contenido líquido del interior de la célula y no solo su envoltura.

Recién con el perfeccionamiento de las lentes, uso de lentes de inmersión y de colorantes, entre 1820 y 1890 , es cuando comienza a surgir la biología celular como protociencia. Es así como en 1838, en que el botánico Matthias J. Schleiden confirma que las plantas están formadas por células y luego, en 1839, Theodor Schwann en su obra "Mikroskopische Untersuchungen...der Thiere Wachstum und Pflanzen" (Investigaciones microscópicas sobre la similitud en la estructura y el crecimiento de la fauna y de la flora) publica que los componentes de los diversos tejidos animales están compuestos también por células, demostrando estas descripciones en conjunto, la unidad existente en todo el mundo vivo ${ }^{3-6}$.

Posteriormente, los estudios de Robert Remak (1815-1865) y Rudolf Virchow (1821-1902) repararon el error acerca del origen de nuevas células, demostrando que las células de todos los tejidos se formaban por división de células preexistentes (lo que dio lugar al famoso aforismo Omnis cellula e cellula, acuñado por Virchow). En conjunto, estos estudios derrumbaron la idea hasta entonces ampliamente afianzada sobre la generación de novo de nuevas células desde materia intercelular inerte $e^{3-4}$.
Aunque hoy en día, la biología en general y la biología celular en particular gozan de una excelente reputación como disciplinas científicas, su nacimiento no estuvo exento de dificultades. Hasta bastante después de la Segunda Guerra Mundial, solo eran aceptadas como "ciencias" propiamente tales, la ciencias exactas, es decir, la matemática, la física, la química y la astronomía ${ }^{5}$. La aproximación experimental se consideraba prácticamente como el único método realmente científico, las ciencias "descriptivas" como lo fue la biología en sus inicios (como cualquier otra ciencia), fueron consideradas como ciencias de segunda clase. Como ejemplo, Ernst Mayr (19042005), eminente biólogo evolutivo y filósofo de la ciencia alemán, en su libro "Así es la Biología", de 1998, relata que en los años que estudió Medicina en las universidades alemanas -siendo los investigadores alemanes los padres de la teoría celular-, no existía una asignatura denominada "biología" y que lo que hoy se incluye en cursos de esta materia, se enseñaba en los departamentos de Zoología y Botánica ${ }^{5}$. Hasta hoy, podría ser un resabio de la "juventud" de esta ciencia el que no exista un Premio Nobel de Biología.

\section{La histología como precursora de la biología celular}

Se considera como el padre de la Histología moderna al francés Xavier Bichat (1771-1802). En su obra "Traité des membranes" (Tratado de los tejidos), publicada en 1799, describió 21 tipos de tejidos elementales que componen el cuerpo humano. En 1857, Franz Leydig (1821-1908) publicó su famoso libro de Histología "Lehrbuch der Histologie des Menschen und der Thiere" (texto de histología humana y animal), que constituyó el primer trabajo de histología comparada. En este texto enseñó que los componentes fundamentales de toda célula eran la membrana, el contenido y el núcleo. Es interesante destacar que la membrana plasmática no puede ser observada utilizando un microscopio óptico, sino que se requiere la resolución del microscopio electrónico que solo se utilizó después de la Segunda Guerra Mundial. En este sentido, en 1861, Max Schulze (1825-1874), estudiando células musculares, no incluyó a la membrana como parte constitutiva de la célula. Esto grafica lo reciente y aún poco unitaria visión 
que existía en dicha época respecto al concepto de célula ${ }^{2,6}$.

Por otra parte, el contenido de las células de embriones ya había sido denominado (1840) como protoplasma por el destacado biólogo checo Juan Evangelista Purkinje (1787-1869), de quien obtienen su nominación ciertas neuronas presentes en cerebelo y corazón. Este protoplasma era considerado como una sustancia especial en esencia diferente a la materia inanimada, en la cual radicaba la esencia de la vida, ideas que defendieron los vitalistas, en contraposición a los fisicistas. Posteriormente, Albert von Kölliker (1817-1905) en su obra "Handbuch der Gewebelehre des Menschen" (Manual de histología humana) publicada en 1863, acuñó el término citoplasma. Dado que el estudio de sus componentes por parte de la bioquímica y la microscopía electrónica descartó que hubiera alguna naturaleza especial en él, el término citoplasma reemplazó al de protoplasma, consolidando así el cambio conceptual respecto a su composición y, de esta forma, respecto a la naturaleza de lo vivo ${ }^{2,3,6}$.

\section{Los maestros precursores directos de la biología celular en Chile}

Es notable el hecho de que tan temprano como en 1827, nuestro afamado erudito y literato don Andrés Bello haya publicado en la Revista Repertorio Americano un artículo de divulgación científica traducido del inglés y titulado Vida y Organización $n^{7}$. En él describía al tejido celular presente en los animales vertebrados como compuesto de pequeñas celdas o menudísimos glóbulos. Luego comentaba sobre los animales infusorios, retratándolos como glóbulos aislados transparentes y se asombraba expresando lo siguiente: "Pero lo más curioso es que este átomo animado es precisamente de la misma forma y magnitud que los glóbulos elementales de que se componen los tejidos primitivos. Cosa maravillosa por cierto! Los cuerpos de los animales más perfectos se componen, como acabamos de ver, de cierto número de tejidos: cada tejido en un agregado de glóbulos; y la criatura más simple que goza de existencia independiente no es otra cosa que un glóbulo del todo semejante a los que, combinados en millares de millares, forman las máquinas vivientes más complicadas y perfectas". Cabe insistir, resguar- dando la rigurosidad histórica, que este artículo es una traducción casi literal de un artículo en inglés publicado en la revista Westminster Review en 1827, relatando las investigaciones del destacado zoólogo inglés, radicado en Francia, Henri Milne Edwards (1800-1885) ${ }^{8}$. Lo notable de esta publicación no es solo su estilo y claridad, sino que deslumbra la precoz percepción que tuvo Andrés Bello respecto de entender la célula como la unidad fundamental de lo vivo. Esto evidencia a Bello no solo como un humanista de amplio bagaje cultural, sino que, además, demuestra su sagaz visión para aquilatar uno de los aspectos centrales de la ciencia que se encontraba en ciernes; efectivamente, la teoría celular de Schleiden y Schwann saldría a la luz casi una década más tarde. Así, es posible que Andrés Bello, imbuido del espíritu del iluminismo, haya sido el primer intelectual americano que pudo conocer desde una fuente original los esbozos de la teoría celular en ciernes en Europa, para luego difundirla a la naciente América Hispana, siempre anhelante de nuevos conocimientos.

\section{José Juan Brunner (1825-1899)}

Un precursor casi desconocido de los estudios histológicos en Chile fue el médico alemán, graduado en Jena, Dr. José Juan Brunner. Lo poco que sabemos de él proviene principalmente de los datos que nos legó el Dr. Orrego Luco en su obra "Recuerdos de la Escuela" ". Allí menciona que el Dr. Brunner vivía en una quinta de la calle de Lira cerca de la Alameda. Dice sobre él: "Brunner vivía en su gabinete, en medio de sus libros, en su gran laboratorio, haciendo estudios químicos, inclinado sobre un hermoso microscopio". Se ha conservado, además, su discurso de incorporación a la Facultad de Medicina titulado: "Fragmentos de una Higiene pública de Santiago", en el ejemplar de los Anales de la Universidad de Chile de 1857. Según Orrego, el Dr. Brunner habría sido el primer profesor que enseñó esta materia en Chile (aunque no fue profesor de Histología en la universidad, sino que dictó un curso privado). Es posible que, habiéndose formado en Alemania en la época en que recién había germinado la teoría celular, haya aprendido los fundamentos de esta nueva teoría de sus maestros y la haya divulgado entre sus escasos discípulos en Chile. 


\section{José Joaquín Aguirre Campos (1822-1901)}

En la misma obra de Orrego Luco se menciona que el afamado Dr. José Joaquín Aguirre Campos (1822-1901), tal vez siguiendo la senda iniciada por el Dr. Brunner, inició un curso privado de Histología para los alumnos de la Facultad de Medicina. Dice, además: "Entre los libros del Dr. Aguirre destacaba un Tratado de Microscopía de Robin (Charles Robin 1821-1885; destacado opositor en Francia a la teoría celular), entre sus instrumentos un microscopio de fábrica francesa y una colección de preparaciones microscópicas encargadas a Paris, en las que se podían estudiar los tejidos y la estructura de los órganos" . Con el fin de facilitar estos estudios, el Dr. Aguirre publicó un "Manual sobre Anatomía Microscópica e Histología" en $1870^{10}$. Dado su interés histórico, se citarán algunos pocos párrafos de esta obra de la cual existe solo una copia en la Biblioteca Nacional. En la introducción se describen los elementos figurados (con forma) y los no figurados (materias amorfas). Entre los elementos figurados menciona tan solo cuatro tipos: las células, las fibras, los tubos y una sustancia homogénea con cavidades. De las células dice lo siguiente: "son elementos anatómicos más o menos redondeados, esparcidos en los tejidos i encerrando habitualmente un núcleo". A continuación: “...la célula está formada por una masa fundamental llena o teniendo una cavidad. Su pared es ordinariamente mui delgada y aparece en el microscopio bajo la forma de una linea circular". "Contra lo que se creia en otro tiempo, la mayor parte de las células no tiene cavidad, i el contenido es de una densidad igual a la de la pared". Como se puede claramente evidenciar, aún no había madurado la idea de considerar a la célula como la unidad fundamental de la materia viviente ni tampoco su subestructura fundamental, pero ya se hablaba de ella como elemento central de la anatomía microscópica.

\section{Vicente Izquierdo Sanfuentes y el desarrollo de la teoría celular en Chile}

Vicente Izquierdo Sanfuentes (1850-1926) nació en el seno de una acaudalada familia chilena que entre sus propiedades disponía de una hacienda en el sector de Lo Arcaya de Pirque (Figura 1). Desde muy niño se habituó a recorrer sus tierras familiares en ese sector, interesándose rápidamente por la observación de la naturaleza. Posteriormente, realizó sus estudios de humanidades en el Instituto Nacional, siendo uno de sus maestros favoritos el doctor Rodulfo Philippi. Claramente, en esa etapa de su vida sus ramos de preferencia eran los del área científica ${ }^{11}$. Obtuvo posteriormente su grado de Bachiller en Humanidades el 9 de enero de 1869. Hay que recordar que en esa época el Bachillerato en Humanidades era un examen obligatorio para el ingreso a las carreras universitarias. Luego, por decisión familiar, ingresó a la carrera de Leyes en la Facultad de Derecho de la Universidad de Chile, obteniendo su grado de Bachiller en Leyes con fecha 27 de diciembre de 1872. Posterior a sus estudios de leyes, pero siguiendo esta vez sus propias inclinaciones, ingresó a la Facultad de Medicina de la Universidad de Chile, obteniendo su grado de Bachiller en Medicina con fecha 12 de marzo de 1875. Estudios que normalmente duraban cuatro años los había realizado solo en dos (1873-1874). Ya con su título de Bachiller en Medicina fue becado por el gobierno para estudiar la nueva disciplina de Histología en Alemania. Estudió primero en la Universidad de Leipzig (1875-1877), bajo la

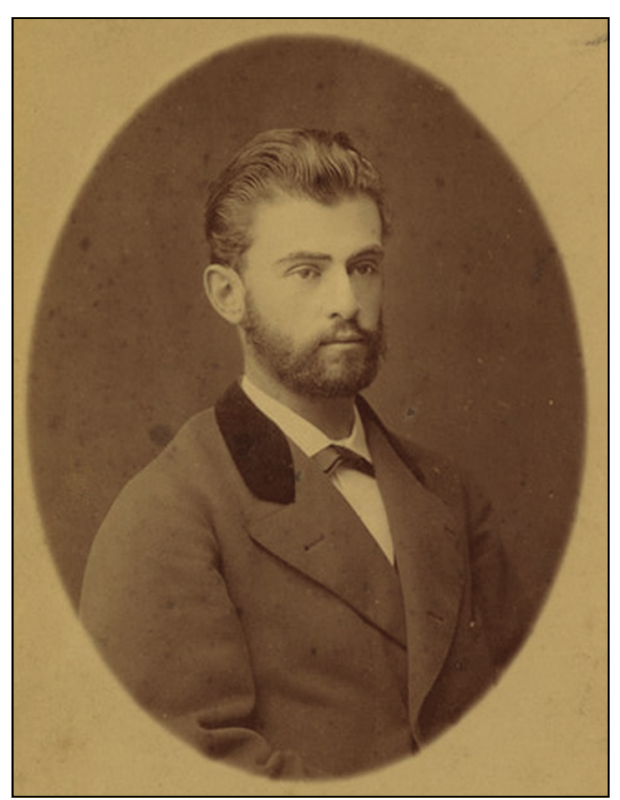

Figura 1. Retrato del joven Dr. Vicente Izquierdo Sanfuentes. Colección Museo Nacional de Medicina, Facultad de Medicina, Universidad de Chile. 
dirección del afamado investigador Wilhelm Hiss, quien trabajaba en la histogénesis del sistema nervioso. Después se trasladó a Estrasburgo (1877-1880), donde trabajó en el laboratorio de Wilhelm Waldeyer, compenetrándose allí de las nuevas técnicas histológicas aplicadas al sistema nervioso. Se graduó de Doctor en Medicina (es decir, médico) con su tesis titulada: "Beiträge zur Kenntnis der Endigungen der sensiblen Nerven" (Contribución al conocimiento de la terminación de los nervios sensitivos). Esta tesis de pregrado fue publicada en la ciudad de Estrasburgo en 1879 y destacaba por sus finas observaciones realizadas sobre las terminaciones sensitivas en la córnea de conejo, pico de pato y genitales de conejo ${ }^{12}$. El doctor Izquierdo retornó a Chile a fines de 1879, en plena guerra del Pacífico, obteniendo su grado de Licenciado en Medicina el 26 de diciembre de 1879 y luego, casi inmediatamente, su título de Médico-Cirujano, el 5 de enero de 1880. Al año siguiente fue nombrado profesor de Histología con fecha 17 de marzo de 1881. Sin embargo, por varias razones, incluyendo la falta de materiales adecuados para la enseñanza de dicha disciplina, especialmente microscopios, comenzó recién a dictar su curso en marzo de 1883.

El destino quiso que, del segundo curso de Histología del Dr. Izquierdo dictado en 1884, se conserven aún los apuntes manuscritos de uno de sus más destacados alumnos, el doctor Dr. Alejandro del Río Soto Aguilar, primer catedrático de Bacteriología ${ }^{13,14}$. El curso se iniciaba con las siguientes definiciones: "Histología es el estudio de los tejidos que se encuentran en el cuerpo humano y en general en un ser vivo". "El estudio que nos ocupa actualmente es el de la Histología Animal. Para él nos servimos del instrumento llamado Microscopio que no solo nos da a conocer las formas (morfología), sino también su composición química (histoquímica)". Casi de inmediato, en la misma lección, introducía el concepto moderno de la célula: "Los elementos anatómicos diferentes entre sí no son muy numerosos generalmente. Son casi siempre agrupamientos, modificaciones o derivaciones y si nos remontamos de causa en causa vemos que todas se derivan de la célula". Y continuaba: "Además de las células encontramos en todas las partes de un animal la sustancia intercelular, de manera que podemos decir que todo animal está formado de células y de inter-células [sic]. Los anatómicos opinan que la sustancia intercelular es producto de la actividad vital de las células". En la tercera lección se describía ya la estructura íntima de cada célula: "si examinamos con el suficiente aumento a este cuerpo de la célula vemos que está formado de afuera a adentro, primero por la membrana de envoltura; por el protoplasma; por el núcleo y a veces por el nucléolo" (Figura 2).

Es evidente con esto, que la moderna teoría celular había arribado a las costas de Chile. En sus siguientes lecciones sistematizó los principales componentes celulares de cada órgano/sistema como se puede observar en las siguientes imágenes (Figuras 2 a 5). Las imágenes estampadas en el cuaderno de apuntes del Dr. Alejandro del Río son realmente bellísimas y, seguramente, semejantes a las confeccionadas por el Dr. Izquierdo en los antiguos pizarrones de la Escuela de Medicina de calle San Francisco, utilizando tizas de variados colores $^{15}$.

Sin lugar a dudas, el doctor Izquierdo, embebido de todos los conocimientos que pudo adquirir de sus excelsos maestros teutones, introdujo definitivamente el estudio de la célula en Chile. Fue el primer chileno en internarse en las profundidades del átomo de la biología, aunque no se debe olvidar el preámbulo de los doctores

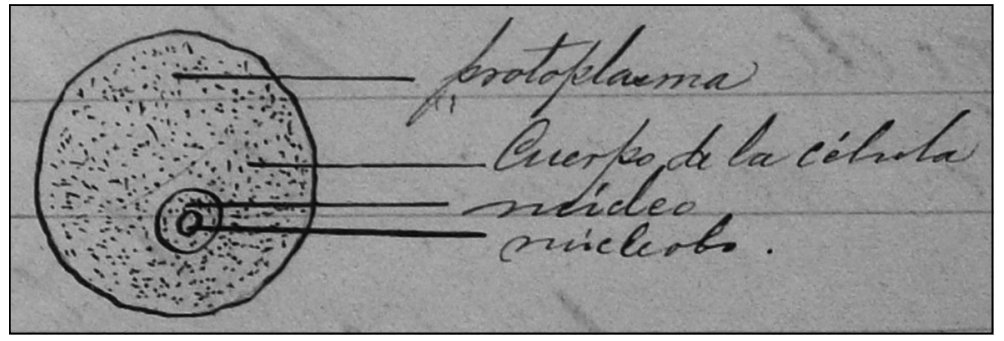

Figura 2. Diagrama de una célula. Apuntes de Histología del Dr. Alejandro del Río. $2^{\circ}$ Curso de Histología de 1884. Colección Museo Nacional de Medicina, Facultad de Medicina, Universidad de Chile. 


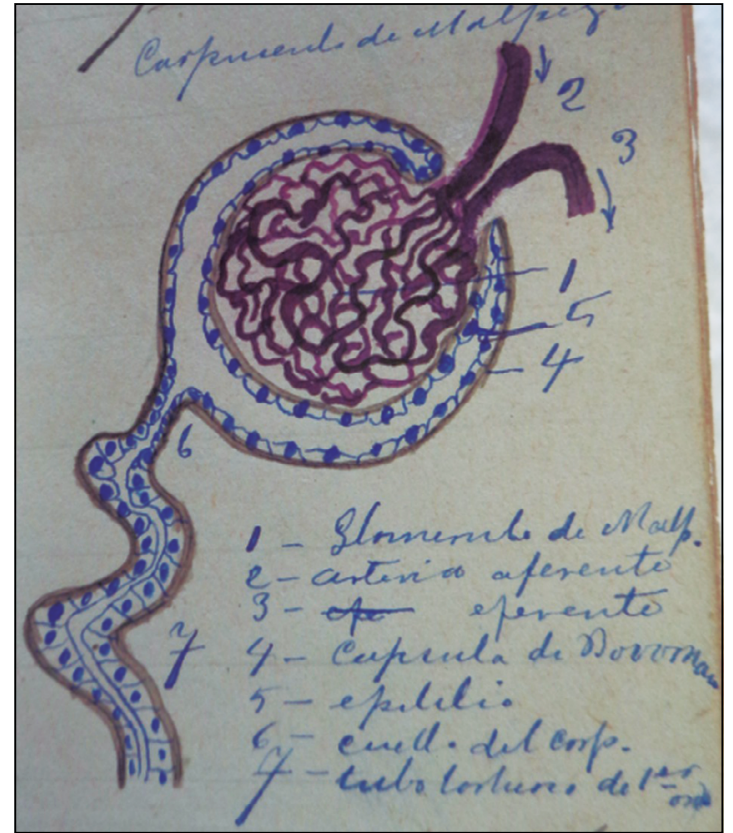

Figura 3. Diagrama del glomérulo renal. Apuntes de Histología del Dr. Alejandro del Río. $2^{\circ}$ Curso de Histología de 1884. Colección Museo Nacional de Medicina, Facultad de Medicina, Universidad de Chile.

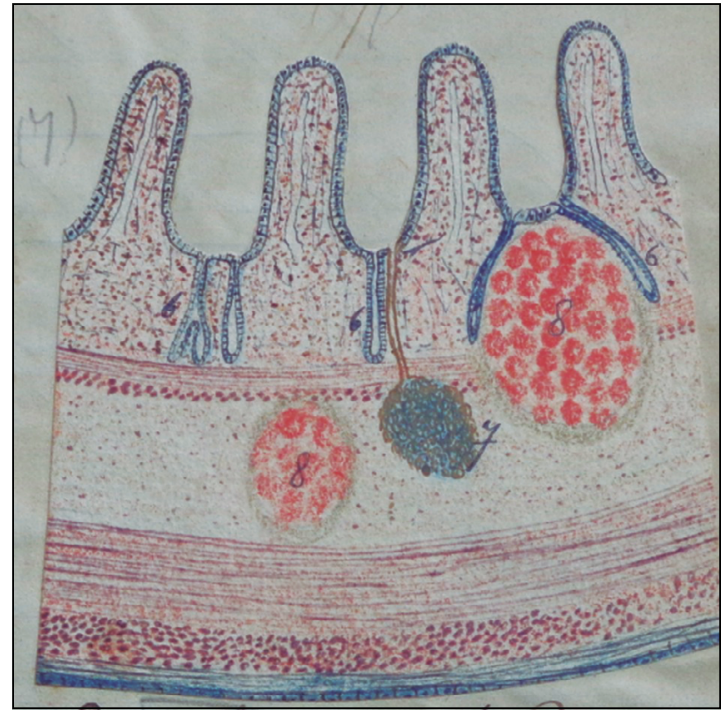

Figura 4. Diagrama de la mucosa intestinal. El número 8 designa placas de Peyer. Apuntes de Histología del Dr. Alejandro del Río. $2^{\circ}$ Curso de Histología de 1884. Colección Museo Nacional de Medicina, Facultad de Medicina, Universidad de Chile.

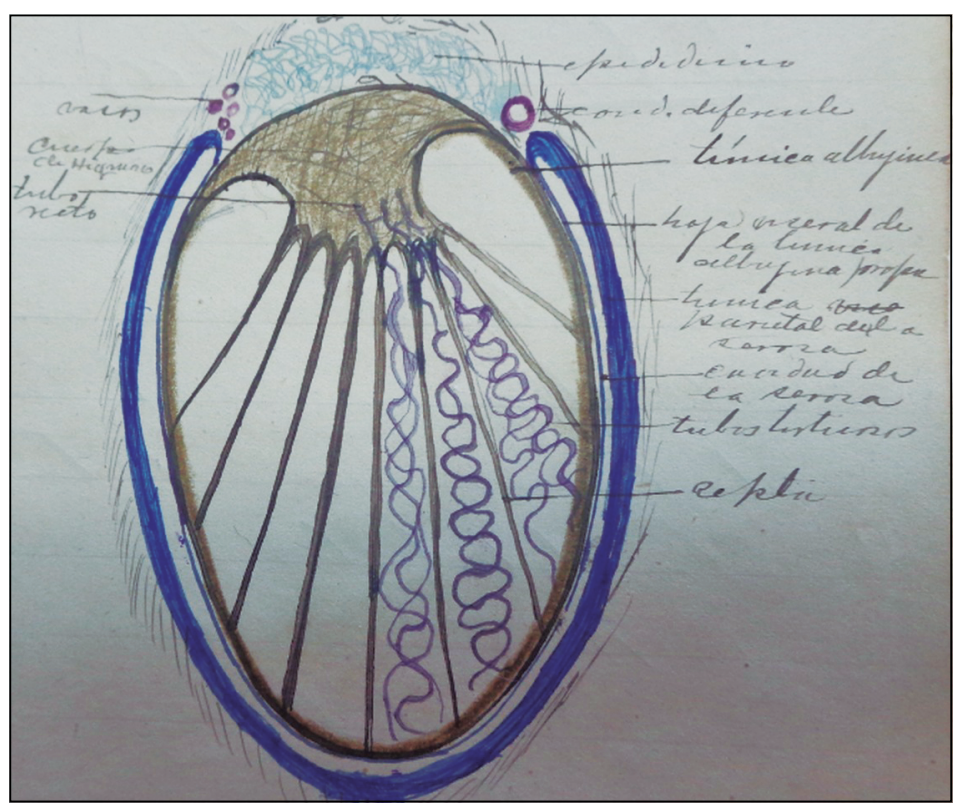

Figura 5. Diagrama del corte de un testículo. Apuntes de Histología del Dr. Alejandro del Río. $2^{\circ}$ Curso de Histología de 1884. Colección Museo Nacional de Medicina, Facultad de Medicina, Universidad de Chile. 
Philippi, Brunner y Aguirre. Como culminación de su carrera académica, el Dr. Izquierdo fue elegido Decano de la Facultad de Medicina por el período 1909-1917. Los discípulos y herederos del Dr. Izquierdo difundieron este hermoso tesoro y cimentaron las bases de esta disciplina, transmutando posteriormente su nombre a Biología General o Celular.

\section{Epílogo}

El Dr. Vicente Izquierdo puede evidentemente ser considerado como el primer biólogo celular de Chile. Además, fue un gran naturalista, investigador, docente y humanista, formando más de treinta generaciones de médicos y discípulos en su campo, quienes difundieron su legado. Su sucesor en la cátedra de Histología entre 1918 y 1939 fue el distinguido biólogo italiano Dr. Juan Noé Crevani (1877-1947). El Dr. Noé había llegado a Chile a fines de 1912 y se hizo cargo de la Cátedra de Zoología Médica en 1913. El Dr. Noé comenzó su curso de Zoología en 1913, modernizando y modificando completamente los contenidos de la cátedra, sin embargo, mantuvo su nombre incólume hasta 1925 en que la subdividió en tres partes. En 1926 eran ya una realidad: una Cátedra de Biología General a nivel del primer año de Medicina, una Cátedra de Embriología y Anatomía Comparada en el segundo año de la Carrera y una Cátedra de Parasitología en el tercer año de la carrera, todas bajo su férreo liderazgo. Es así como la disciplina denominada Biología General o Celular se instauró en nuestro país.

Agradecimientos: Quisiéramos agradecer a varios colegas del Programa de Microbiología del Instituto de Ciencias Biomédicas (ICBM) que accedieron a leer y criticar este trabajo y así ayudaron a mejorar sustancialmente su presentación. También agradecemos al Museo de Historia de la Medicina de la Facultad de Medicina de la Universidad de Chile por habernos facilitado los apuntes manuscritos del Dr. Alejandro del Río con sus magníficas imágenes.

\section{Referencias}

1. Ledesma IM. La introducción de los paradigmas de la biología en México y la obra de Alfonso L. Herrera. Historia Mexicana 2002; 52 (1): 201-40.

2. Vial Correa JD. La teoría celular en los orígenes de la biología moderna. Editorial Universitaria, Santiago de Chile, 1982.

3. Radl EM. Historia de las teorías biológicas. Alianza Editorial, Madrid, España, 1988.

4. Papp D. Ideas revolucionarias de la ciencia. Su historia desde el Renacimiento hasta promediar el siglo XX. Tomo I, Editorial Universitaria, Santiago de Chile, 1975.

5. Mayr E. Así es la biología. Editorial Debate SA, Madrid, España, 1998.

6. Harris H. The birth of the cell. Yale University Press, New Haven, USA, 1999.

7. Bello A. Vida y organización. Repertorio Americano, 1827. Disponible en: cdigital.dgb. uanl.mx/ [consultado el 16 de marzo de 2019].

8. Milne-Edwards MH. Life and Organization. The Westminster Review, tomo VII, 1927. Disponible en: https:// catalog.hathitrust.org/. [Consultado el 10 de marzo de 2019].

9. Orrego Luco A. Recuerdos de la Escuela. Rev Med Chile 1923; 51: 145-63. Disponible en: http://www.memoriachilena.gob.cl. [Consultado el 10 de abril de 2019].

10. Aguirre JJ. Elementos de anatomía general o de histolojía. Imprenta de la República, Santiago, Chile, 1870.

11. Campos E. Una vida por la vida. Vicente Izquierdo Sanfuentes. Un gran médico chileno y su época (1850-1926). Ed. Universidad Católica de Chile, Santiago, Chile, 1996.

12. Izquierdo V. Beiträge zur Kenntnis der Endigungen der sensiblen Nerven. Strassburg, Alemania, 1879. Disponible en: https://descargarlibros.xyz/beitrage-zur-kenntniss-der-endigung-der-sensiblen-nerven-2141382.html [Consultado el 1 de marzo de 2019].

13. Apuntes de Histología del Dr. Alejandro del Río. 1884. Colección Museo Nacional de Medicina, Facultad de Medicina, Universidad de Chile.

14. Osorio CG. Sobre el origen de la bacteriología experimental en Chile. Rev Med Chile 2010; 138: 913-919. Disponible en: https://scielo.conicyt.cl/scielo. [Consultado el 15 de marzo de 2019].

15. Osorio CG. Historia de la Escuela de Medicina de la Cañadilla. Rev Med Chile 2013; 141: 1484-8. Disponible en: https://scielo.conicyt.cl/scielo. [Consultado el 10 de marzo de 2019]. 